\title{
Is Private Production of Public Services Cheaper than Public Production? A meta-regression analysis of solid waste and water services
}

\author{
Germà Bel, Xavier Fageda and Mildred E. Warnerd
}

- Germà Bel is Professor at Universitat de Barcelona and Guest Professor at Barcelona Graduate School of Economics. Departament de Política Econòmica, Avd. Diagonal 690, 08034 Barcelona, Spain, gbel@ub.edu.

- Xavier Fageda is Assistant Professor at Universitat de Barcelona. Departament de Política Econòmica, Avd. Diagonal 690, 08034 Barcelona, Spain, xfageda@ub.edu.

- Mildred E. Warner is Professor at Cornell University. Department of City and Regional Planning, 215 W. Sibley. Cornell University. Ithaca, NY 14853, USA; e-mail mew15@cornell.edu .

\begin{abstract}
Privatization of local government services is assumed to deliver cost savings but empirical evidence for this from around the world is mixed. We conduct a meta-regression analysis of all econometric studies examining privatization for water distribution and solid waste collection services and find no systematic support for lower costs with private production. Differences in study results are explained by differences in timeperiod of the analyses, service characteristics, and policy environment. We do not find a genuine empirical effect of cost savings resulting from private production. The results suggest that to ensure cost savings, more attention be given to the cost characteristics of the service, the transaction costs involved, and the policy environment stimulating competition, rather than to the debate over public versus private delivery of these services.
\end{abstract}

Keywords: Privatization, contracting-out, costs, local governments, meta-regression analysis.

JEL classification: L33, R51, H72, C25.

Acknowledgments: Germà Bel and Xavier Fageda are thankful for support provided for this research from the Spanish Commission of Science and Technology (SEJ 2006-04985), and from the Fundación Rafael del Pino. Mildred Warner's privatization research was supported by funding from the US Dept of Agriculture National Research Initiative (NYC-121524). An earlier version of this paper was presented at the American Public Policy and Management Conference Los Angeles, CA (November 6, 2008). We are thankful for comments from Daniel Albalate, Trevor Brown, Raymond Gradus, and Eoin Reeves. 


\section{INTRODUCTION}

One of the promises of privatization is that it offers efficiency gains and reduces the costs of public service delivery. However, after more than three decades of experimenting with contracting out local government services, the evidence for cost savings is mixed. Some studies find that private ownership does indeed result in a reduction in costs, but others fail to find statistically significant differences between public and private ownership. Descriptive meta-analyses conducted by Boyne (1998), Hirsch (1995), and Hodge (2000) report savings in some cases but not in others, with the weight of evidence failing to support systematic cost savings for private service delivery. Interestingly, the literature has increasingly turned its attention to factors that might undermine savings from privatization such as hefty transaction costs (Brown \& Potoski, 2003, 2005), market concentration, and the lack of competition (Bel \& Costas, 2006; Dijkgraaf \& Gradus, 2007). Most of the empirical economic literature has focused on the delivery of solid waste services and water distribution, the two local government services with the greatest contracting experience. Recent descriptive meta-analyses of these two services report limited evidence of cost savings-especially among the most recent studies (Bel \& Warner, 2008).

The analysis presented here constitutes a systematic test of cost differences across a range of studies of public and private production controlling for several variables. In our study, we conduct a meta-regression analysis of 27 empirical studies that compare the costs of private and public production for large samples of municipalities with different attributes. We focus our attention on cross-sectional empirical analyses that use multivariate methods to study the two local services with the most contracting experience: solid waste collection and water provision. To date we have found 38 published papers and working paper on such studies conducted in the US, the UK, and around the world, forming the population from which we select our sample. By statistically analyzing the characteristics of each regression model, we are able to assess the weight of evidence concerning the costs of public or private production.

Our empirical analysis is based on studies that compare the costs of public and private production rather than studies that examine the impact of privatization within services as they change ownership or between services that have changed ownership and those that have not. To gauge the impact of privatization on costs as accurately as possible, a time-series approach to assess the before and after effects of the change in ownership would be preferred. However, only one 
paper in the extant body of literature (Lynk, 1993) used such an approach ${ }^{1}$ to determine the impact of the change in ownership on efficiency. Inevitably, a meta-regression analysis is limited to the available empirical evidence and, thus, our goal is to assess whether private production is less costly than public production when controlling for attributes that can be compared across studies.

Costs are a driving factor in the decision concerning the form of service delivery (Bel \& Fageda, 2007). Our objective is to analyze whether privatization (private delivery) ${ }^{2}$ constitutes an effective alternative for reducing costs in the provision of solid waste and water distribution services at the metropolitan scale. Expectations for cost savings stem primarily from the notion that competition increases the pressure to achieve efficiency at lower costs. However, water distribution is a service characterized by high asset specificity and tends toward a natural monopoly with few expectations of competition. This might account for the fact that there have been relatively few instances of privatization in water services. Solid waste collection tends to have more competition and more common privatization. However, considerable industry concentration has been seen in the waste sector over the last 20 years (Bel \& Costas, 2006; Davies, 2007; Dijkgraaf \& Gradus, 2008; Warner \& Bel, 2008). Therefore, in neither of the two service areas is competition expected to persist over time.

One primary benefit from opening up public services to competition from the private sector may be efficiency improvements generated among public producers as a response to competitive pressure and benchmarking from private providers (Hatry, 1988; Bel, 2006). Hence, one likely effect of privatization is that it can spur improvements in public sector efficiency. This could lead to an underestimation of the dynamic benefits of the broader privatization process. However, we are unable to test for competition, market dynamics, or public sector improvement in our metaregression analysis because almost none of the empirical studies considered here controlled for these factors.

Our meta-regression analysis does not reveal a systematic relationship between cost savings and private production. Indeed, we find that the most recent studies, those from the US, and those on water services, are less likely to show any savings. The rest of this paper is organized as follows. First,

\footnotetext{
${ }^{1}$ The specific characteristics of water privatization in England and Wales allowed Lynk (1993) to adopt this approach. Water is a provincial service in England and Wales, and privatization was undertaken simultaneously in 1989, when 10 public agencies were privatized. Lynk compared the efficiency of these 10 agencies before privatization and of the corresponding private firms following privatization.

2 Privatization or contracting out separates the provision decision (which remains public) from the production or actual delivery of the service (which can be contracted out or privatized). Pure privatization of municipal services, or service shedding, is rare. All the studies in our sample examine cost differences between public and private production (via a contract or concession agreement). In both cases, the government retains responsibility for service delivery.
} 
we review the literature related to the relationship between privatization and costs. Then, we explain the methodology and describe the meta-regression analysis of the results reported in previous studies. Finally, we present a discussion of our results in light of our theoretical concerns.

\section{RELATIONSHIP TO THE THEORETICAL AND EMPIRICAL LITERATURE ON PRIVATIZATION AND COSTS}

In this section, we address several reasons why privatization may or may not produce cost savings. Issues related to the dilemma between competition and monopoly and between public and private ownership have been emphasized by public choice and property rights literatures. These approaches consider the incentives available to managers and the role that competition can play in reducing excessive public supply of public services (Niskanen, 1971), or in providing greater incentives for cost reduction under private property (Shleifer, 1998), and thus reducing costs. Other approaches have put more emphasis on the effects of the principal-agent problems associated with privatization. In this way, transaction costs and industrial organization literatures are more concerned with the nature of the service, and put more emphasis on the importance of the costs of contracting and monitoring (Williamson, 1999), the importance of economies of scale (Donahue, 1989), and market structures (Vickers \& Yarrow, 1988). We assess the empirical evidence of privatization's cost savings through these theoretical lenses. This reflects our awareness that a comprehensive theoretical approach that can focus both on actors and on incentives as well as on market and regulatory structure is required to understand why privatization has not delivered cost savings. However, the more recent theoretical propositions (outlined below) have not been incorporated in the extant empirical evidence (especially the earlier studies). Hence, our meta- regression is unable to take full account of all the theoretical insights discussed below.

\section{Competition Versus Monopoly in Service Delivery}

One of the primary ways in which privatization may produce cost savings is by replacing monopoly with competition in the public services market, which is in line with the belief that competition will restrict excessive supply of public services and lower costs. Replacing monopoly with competition can be achieved by assigning contracts to external producers through competitive procedures or by promoting competition between governmental units (Tiebout, 1956; Osborne \& Gaebler, 1992).

Particular consideration to promoting competition is found in the public choice literature, which gives primary emphasis to incentives and is centered on the view that politicians and bureaucrats behave like the typical neoclassical individual (Niskanen, 1971). Hence, the central actors 
in the government service delivery process seek to maximize their personal utility and interests. If public service delivery is a monopoly in the hands of politicians and bureaucrats, the result will be an excess supply of public services and consequently, inefficiency, because the services will be managed with the objective of extracting material rents and political power (Savas, 1987). These insights provide a strong rationale for the expectation of cost savings from privatization-provided competition is present. However, public services are at best quasi-markets with a limited number of alternative private suppliers (Lowery, 1998; Sclar, 2000; Warner \& Hefetz, in press). Competitive markets rarely exist for public services and this undermines the basis for cost savings. Thus, governments need to play a role in creating competition in public service markets and in careful monitoring to ensure cost savings (Warner \& Hebdon, 2001; Warner \& Hefetz, 2008).

Private Property, Property Rights, and Cost Reducing Innovations

Grossman and Hart (1986) and Hart and Moore (1990) argue that asset ownership gives the owner control and bargaining power in situations in which the contractor cannot perfectly foresee the evolution of the activity (Shleifer, 1998). Ownership is an important factor because it confers the right to obtain the benefits from actions related to the assets such as profit, as well as the benefits from innovation and efficiency gains. Bureaucrats have control rights under public ownership, but they do not enjoy property rights, and thus cannot directly benefit from the profits generated by cost reduction. By contrast, private owners have control rights and can appropriate benefits from cost reduction (Shleifer \& Vishny, 1994).

Hart, Shleifer, and Vishny (1997) apply the theory of incomplete contracts and property rights to the choice between public or private production of public services. Their study suggests that under private production, incentives exist to reduce costs at the expense of quality. Under this framework, incentives work as follows:

a) With private ownership, the manager has incentives to reduce costs through quality deterioration. The manager does not need authorization from the government, which will bear the political costs of quality reduction. To give the manager incentives to innovate to increase quality, the manager would need to negotiate price increases with the government to ensure compensation for his investment. Most likely, this negotiation will not result in a full appropriation of benefits from the innovation, which reduces the manager's incentives to innovate.

b) Under government ownership, incentives work in the opposite direction. Because the manager is government-employed, he will take into account potential quality erosion when 
considering the implementation of cost reducing innovations. In addition, the public manager will need government permission for any innovation he wants to undertake (either quality improvement or cost reduction). In the absence of a pay-for-performance scheme, the public manager will not fully benefit from the results of innovation.

Overall, private ownership offers more incentives for cost reduction, but these incentives can induce quality erosion. Ensuring quality under privatization requires increased oversight, which can blur the line between public and private ownership (Guttman, 2000; Bozeman, 1987). As the difference between public and private ownership disappears, the potential for cost savings from private ownership may disappear as well.

Principal-agent Problems, Transaction Costs, and Market Structure Conditions

According to the seminal work by Ronald Coase (1937), transactions occur inside the firm when market transactions incur higher costs than internal ones. The transaction costs approach takes the choice to "make" or "buy" within a private firm framework and applies it to government decisions concerning public services delivery. Following Williamson (1999), transactions have three basic dimensions: (1) uncertainty regarding how the transaction develops, and its results; (2) the frequency with which transactions are repeated; and (3) the relative requirement of long-term investments specifically related to the transaction, or sunk costs. Because of these factors, the institutional organization required to establish and apply contracts can be very complex.

The theoretical analysis of privatization and contracting out uses the concept of transaction costs in a broad sense, which includes administrative costs as well as costs from incomplete contracts. In their theoretical analysis of the choice between public and private production, Sappington and Stiglitz (1987) argue the main factor explaining the choice of production form is a function of the transaction costs derived from the delegation of authority. Monitoring and control play a central role, and cost minimization refers to both the production and transaction costs implied by contracting out. Cost savings are likely to emerge when transactions costs are not great. Thus, depending on the characteristics of the specific service (with respect to the three dimensions above), the likelihood of savings will vary.

Stein (1990) used this approach to classify local government services and assess the form of delivery. Transactions costs have been used to explain government choice in the decision to contract out (Nelson, 1997; Sclar, 2000; Hefetz \& Warner, 2004, 2007). While some authors downplay contracting costs and argue that the costs of bureaucracy are higher (Savas, 1987; Eggers \& O'Leary, 1995; Osborne \& Plastrick, 1997), others find transactions costs to be significant factors in 
explaining decisions to privatize or reinternalize production (Ferris \& Graddy, 1994; Lowery, 1998; Kavanagh \& Parker, 1999; Brown \& Potoski, 2003; Hefetz \& Warner, 2004, 2007; Bel \& Fageda, 2008; Levin \& Tadelis, in press). Cost savings expectations, when considered from this perspective, are dependent on the nature of the service and local market conditions.

The industrial organization literature shares with the property rights approach the core relevance given to the relationship between incentives and ownership. However, it also emphasizes the duality between principals and agents, as in the transaction cost approach. The central problem here is how incentives might encourage the manager to behave in accordance with the owner's objectives. When comparing public and private ownership, the ability to align managerial actions with ownership objectives is the rationale for differences in efficiency between private and public ownership.

When there is a strong separation between ownership and management, a few key factors can work as control mechanisms to improve the alignment between the two (Vickers \& Yarrow, 1988). According to the industrial organization literature, private ownership is preferred to public ownership when (1) owners benefit from devoting time and money to obtaining the information needed for supervision, (2) firms can be taken over, and (3) firms are at risk of bankruptcy. The way in which the market structure influences how these three factors work is extremely important. These factors are more common in competitive markets that are not subject to strong government regulation (Kay \& Thompson, 1986; Vickers \& Yarrow, 1988). In markets prone to concentration, the impact of factors that align principal and agent objectives is weak. In those services characterized by scale economies, market concentration trends will emerge. The same is true of markets in which strong government regulation persists after privatization. Dnes (1995) emphasized the potential advantage incumbents enjoy in markets characterized by long-term specific assets. The industrial organization approach emphasizes the design of contracts and bids to specify properly the conditions that stimulate dynamic competition and thus reduce the likelihood of future monopolization (Laffont \& Tirole, 1993; Bolton \& Dewatripont, 2005).

The industrial organization literature also recognizes that privatization can introduce pressure and incentives for internal reform in those municipalities that retain public service delivery (Hatry, 1988), because including privatization within the menu of available alternatives creates pressure on the public manager similar to that placed on private managers by the risk of bankruptcy (Bel, 2006). In this way, privatization could stimulate efficiency improvements in public production in those services kept under governmental delivery.

Theoretical Expectations 
The empirical studies we analyze in our meta-regression draw on these different approaches (public choice, property rights, transaction costs, and industrial organization) to privatization and costs. By different approaches, we do not imply that they are incompatible or radically distinct. Instead, they differ in their emphases on ownership, competition, principal agent alignment, and market structure when analyzing the relationship between privatization and costs. Our data set contains studies of both solid waste collection and water distribution - two services with different cost structures. Scale economies (related to output) affect solid waste collection, while density economies (related to population density) are critical for water distribution. Fixed assets are required to produce both services, but water distribution has network features associated with a high level of sunk (and specific) investments. Hence, the transaction costs involved in privatizing should be lower for solid waste collection. $^{3}$

Theoretically, we might expect cost savings in both water and waste if competition were present. Competition is a factor common to all four theoretical approaches (albeit of lesser relevance in the case of property rights). However, the emphasis on conditions governing competition and on market dynamics differs between the approaches.

In the case of waste collection, property rights theory suggests private production can be cheaper due to incentives to invest in new technologies. Public choice theory emphasizes the benefits of competition in reducing costs, while transaction cost theory recognizes complete contracts are more likely in waste collection than in water (because of lower asset specificity and less measurement difficulty). Industrial organization theory tends to emphasize the benefits of economies of scale but recognizes the challenges faced by market structures that are prone to concentration. While each of these theoretical perspectives offers possibilities for cost savings, the mixed empirical evidence may be explained by limited competition and technological improvement, and the importance of market structure.

\footnotetext{
${ }^{3}$ In a 2002 survey of public managers in local governments in the US, Brown and Potoski (2005) measure perception of transaction costs from asset specificity and ease of measurement on scales from 1 (low) to 5 (high). The asset specificity of residential and commercial solid waste is at 3 on the scale while water distribution is at 4 . The ease of measurement is 2 for solid waste and 2.4 for water. Thus, both asset specificity and difficulty of measurement are lower for solid waste services than they are for water distribution. Levin and Tadelis (in press) build indicators of contract difficulty, as perceived by U.S. city managers, and find that contract difficulty is above average for water services and below average for waste. Warner and Hefetz (in press) in a national U.S. 2007 survey of transactions costs and competition also find city managers' assessments of asset (AS) specificity and difficulty of contract management (Mgmt) are higher for water (AS = $4.5, \mathrm{Mgmt}=3.5)$ than for waste (AS $=2.9, \mathrm{Mgmt}=2.2$ ). In addition, they measure levels of competition in local government service markets and find that competition for waste is above average at 2.6 providers, while competition for water service is less than one (0.8).
} 
In the case of water distribution, the theoretical predictions are less optimistic. From property rights theory we would expect cost savings, but at the expense of service quality, though if governments maintain careful quality regulation, cost savings through quality reduction in water are unlikely. Competition is harder to achieve due to the fixed network infrastructure on which water delivery depends. As a result, private contracts are usually of longer duration than in other services, and this places incumbents in a strong position in the event of a new tendering process. Transaction cost theory predicts problems due to the long duration of contracts and the large (and sunk) investments that create a high degree of incompleteness in water contracts. Industrial organization theory emphasizes that sunk costs prevent competitive discipline among private providers. Thus, the theoretical basis for cost savings under private production is weaker than it is for waste distribution.

Summing up, two main propositions derived from our theoretical expectations are (1) systematic cost savings with private production are not expected due to problems related to competition and market dynamics, and (2) cost savings with private production will be less frequent for water service than waste collection, due to water service's higher transaction costs (from incomplete contracts) and higher quality protections (preventing quality erosion).

Empirical Background on Lack of Costs Savings

We provide a brief review of the empirical literature to explore potential reasons for the lack of cost savings from privatization. To do this, we focus on the empirical works included in the metaregression that have found either higher costs with private production or no significant difference of costs between public and private delivery. ${ }^{4}$

Papers published in the 1970s and early 1980s in the US offer ad-hoc explanations for the lack of differences in costs between public and private delivery. Mann and Mikesell's (1976, p. 1003) analysis on water suggests that scale of operations is much more important than ownership regarding efficiency. Bruggink (1982, p. 121) offers two basic explanations for the lack of differences in cost: (1) The operation of government firms within hostile "free enterprise" environments exerts continuous pressure on public firms' performance; and (2) public firms attract higher quality management because of factors like longer job tenure. Regarding solid waste collection, Stevens (1978, p. 445) finds that private competitive arrangements are more costly than monopoly

\footnotetext{
${ }^{4}$ Some works that do not find lower costs with private delivery do not provide any discussion of potential reasons for this result. This is the case of Hirsch (1965), Dubin and Navarro (1988), Callan and Thomas (2001) for solid waste, and of Teeples and Glyer (1987) and Byrnes (1991) for water. Two papers, Kemper and Quigley (1976) and Collins and Downes (1977)—both on solid waste—provide some discussion on why private provision (competition in the market) is more costly than municipal provision, but they do not discuss the differences in costs between public and private delivery within municipal (monopoly) provision.
} 
arrangements (either public or private) and attributes this to higher billing costs and extra expenses derived from non-exclusivity within the market area born by the firm under private market arrangements. When comparing public and private monopolistic delivery, Stevens finds that private delivery is less costly in cities over 50,000 inhabitants, but there are no significant differences in cities below 50,000. Stevens' explanation $(1978$, p. 447$)$ is based on the main differences in productivity between private and public providers that come from smaller crews with larger capacity vehicles, as well as lower absentee rates under private delivery. While these differences have a relevant dimension in larger cities, they become non-relevant in smaller cities below 50,000 inhabitants.

The importance of competition to explain costs differences is stressed in the analyses on solid waste collection in the United Kingdom published in the mid 1980s and early 1990s. Domberger, Meadowcroft, and Thompson (1986, pp. 79-80) find that tendering is cheaper than in-house production, but when contracts are awarded by tender, public and private units do not show significant differences in costs. They conclude that competition matters much more than ownership regarding cost savings. Similarly, Szymanski and Wilkins (1993, p. 127) find differences exist between tendering and in-house production with no tendering, but not between different property regimes under tendering. The message is the same as in Domberger, Meadowcroft, and Thompson: Competition is more important than ownership.

Through the current decade many papers have found no differences in costs between public and private delivery. Discussion of the potential reasons for lack of cost differences has become richer. Problems related to transaction costs involved in contracting out are emphasized in the empirical analysis by Kirkpatrick, Parker, and Zhang (2006, pp. 155-158), Bel and Fageda (in press), and Bae (in press). Competition failures, particularly those derived from concentration in the market for private providers, are discussed in Dijkgraaf and Gradus (2003, p. 155; 2007, p. 582), Bel and Costas (2006, p. 20), Bel and Fageda (in press), and Bae (in press). Another factor that may explain the lack of difference in costs between private and public production is the reform of services retained under public delivery spurred by the threat of privatization, as in Estache and Rossi (2002, p. 146-147), Bel and Costas (2006, p. 17), Dijkgraaf and Gradus (2007, p. 583), Bel and Mur (2009, p. 2777), and Bae (in press). Finally, Ohlsson (2003, p. 467) points out that municipalities that choose public delivery have conducted more careful yardstick competition, in the sense that they have done cost analysis. In all, recent empirical analysis that finds lack of differences stresses the importance of competition failures due to concentration, high transaction costs associated with contracting out, and improvement of efficiency in publicly delivered services due to internal reform. 


\section{METHODOLOGY}

We develop a meta-analysis to provide a systematic test for cost differences across a range of studies of public and private production. A major objective of a meta-analysis is to provide a statistical explanation for the differences in results reported in the empirical literature on a given topic (Stanley \& Jarrell, 1989). Meta-analysis provides tests concerning the true effect of the relationship analyzed, along with tests for possible publication bias (Stanley, 2005b).

Meta-analysis is a statistical technique that has been widely used in the social and medical sciences. Since the late 1980s, about 150 meta-analyses of empirical studies have been published on a great variety of issues in economics and economic policy (Connor \& Bolotova, 2006). Some relevant examples include minimum wage effects (Card \& Kruger, 1995), the value of air quality (Smith \& Huang, 1995), productivity spillovers of multinational companies (Görg \& Strobl, 2001), the value of life (Mrozek \& Taylor, 2002), the effect of immigration on wages (Longhi, Nijkamp, \& Poot, 2005), environmental inequities (Ringquist, 2005), the natural rate hypothesis (Stanley, 2005a), cartel overcharges (Connor \& Bolotova, 2006), voter turnout (Geys, 2006), productivity gains of urban agglomeration economies (Melo, Graham, \& Noland, 2009), and factors explaining local privatization (Bel \& Fageda, 2009).

Economics and public policy studies do not use data collected from controlled experiments so meta-analysis is implemented differently in those disciplines than in the medical sciences. Stanley and Jarrell (1989) called the use of meta-analysis in economics "meta-regression analysis" because this methodology is generally applied to data collected from studies employing regression based econometric techniques.

The starting point of our meta-regression analyses is the following equation (Stanley \& Jarrell, 1989):

$$
b_{j}=\beta+\sum \alpha_{k} Z_{j k}+e_{j} \quad j=1,2, \ldots L
$$

where $b_{j}$ is the reported estimate of $\beta$ of the $j$ th study, $\beta$ is the true value of the parameter of interest ${ }^{5}, Z_{\mathrm{jk}}$ are the meta-independent variables that measure relevant characteristics of an empirical study, and $\alpha_{\mathrm{k}}$ are the coefficients associated with those independent variables. In this equation the

\footnotetext{
${ }^{5}$ We mean here by the parameter of interest the coefficient that measures the sign and magnitude of the relationship analyzed; in our case, this parameter is the t-statistic for the coefficient associated with the variable of private production in a regression where the dependent variable is the production costs of the service.
} 
magnitude or significance of the intercept term, $\beta$, will determine whether there is a true effect regarding the relationship analyzed.

The meta-independent variables, $Z_{k}$, will allow us to examine the influence of different study characteristics on the results. For example, if year of data collection is significant then we will have evidence that results of the relationship analyzed are conditioned by the period of analysis.

To tackle any potential problem of heteroscedasticity, Stanley and Jarrell (1989) suggest a transformation of Equation (1). This transformation implies dividing all the terms in Equation (1) by the standard error of the coefficient $b_{j}$. Hence, we obtain the following equation:

$$
\mathrm{T}_{\mathrm{j}}=\mathrm{b}_{\mathrm{j}} / \mathrm{S}_{\mathrm{b}}=\beta / \mathrm{S}_{\mathrm{b}}+\sum \alpha_{\mathrm{k}} \mathrm{Z}_{\mathrm{jk}} / \mathrm{S}_{\mathrm{b}}+\mathrm{e}_{\mathrm{j}} / \mathrm{S}_{\mathrm{b}} \quad \mathrm{j}=1,2, \ldots \mathrm{L}
$$

where $T_{j}$ is the t-statistic of the coefficient $b_{j}$ and $S_{b}$ is the standard error of the coefficient $b_{j}$. Note that the intercept term in Equation (1) and the coefficient associated with the inverse of the standard error $\left(1 / \mathrm{S}_{\mathrm{b}}\right)$ in Equation (2a) should be the same parameter $\beta$. As noted by Stanley (2005b), the inverse of the standard error may be substituted by sample size. Thus, the parameter that measures the true effect is now the coefficient associated with the variable of sample size. In this regard, from an econometric point of view Equation (2a) would lead to the following equation:

$$
\mathrm{T}_{\mathrm{j}}=\alpha_{0}+\alpha_{1} \text { Sample_size }+\sum \alpha_{\mathrm{k}} \mathrm{Z}_{\mathrm{jk}} / \mathrm{S}_{\mathrm{b}}+\varepsilon
$$

This latter Equation (2b) is the basis of our empirical analysis in which the magnitude and statistical significance of $\alpha_{1}$ will provide empirical evidence of the relationship examined. Note here that a standard statistical property is that the magnitude of the t-statistics will vary systematically with sample size (and degrees of freedom) only if there is in fact a systematic empirical effect.

A major concern in meta-regression analysis is to identify the possible existence of publication bias. Indeed, papers are more likely to be published when significant relationships between the variables of interest are found. Studies with statistically significant findings may be more likely to be published, leading to an incorrect conclusion that a policy is effective, when in fact it is not. To detect and correct for possible publication bias in a meta-regression, Stanley (2005b, 2007) suggests the funnel asymmetry test (FAT). The FAT test is based on the statistical property that standard errors of estimates become smaller as the number of observations in the study increases. Hence, studies with larger samples are expected to contain smaller publication biases.

The FAT test estimates the relationship between a study's reported effect and the standard errors of its coefficients. We estimate the following equation: 


$$
T_{\mathrm{i}}=\beta_{0}+\beta_{1}\left(1 / S E_{\mathrm{i}}\right)+\varepsilon_{\mathrm{i}}
$$

where $T$ is a study's reported t-statistic and $1 / S E$ is the inverse of the standard error. Stanley (2005b, 2007) suggests that the statistical significance of the intercept in Equation (3a), $\beta_{0}$, is a test for publication bias and that its sign indicates the direction of this bias. Evidence of publication bias will be found when $\beta_{0} \neq 0$. Additionally, the coefficient $\beta_{1}$ in Equation (3a) provides an estimate of the true empirical effect of the parameter of interest. The independent variable, $1 / S E$, may have some measurement errors that condition the econometric estimates. Hence, the square root of sample size is used as an instrument for the inverse of the standard error. Sample size is not subject to estimation error, and standard errors and sample size are highly correlated. Observed effects should vary randomly around the true value if publication bias is absent. This will be the case if the intercept term of Equation (3a) is not statistically significant. Beyond publication bias, some study's characteristics may influence the t-statistics obtained. Hence, the FAT test may be embedded into multivariate FAT-tests where some other explanatory variables related to study's characteristics are added:

$$
T_{\mathrm{i}}=\beta_{0}+\beta_{1}\left(1 / S E_{\mathrm{i}}\right)+\sum \beta_{\mathrm{k}} \mathrm{X}_{\mathrm{ik}}+\varepsilon_{\mathrm{i}}
$$

The relationship between a study's t-statistic and its degrees of freedom using the logarithmic form can also serve as a meta-significance test (MST) to identify a genuine empirical effect (Stanley, 2005b, 2007). The meta-significance test is based on the statistical property that the magnitude of the t-statistics will vary systematically with the degrees of freedom if there is in fact an overall genuine empirical effect. We estimate the following equation:

$$
\log \left(|T|_{\mathrm{i}}\right)=\alpha_{0}+\alpha_{1} \log (d f)+\varepsilon_{\mathrm{i}},
$$

where $|T|$ is a study's reported t-statistic (in absolute value) and $d f$ is the corresponding degrees of freedom. If we find that $\alpha_{1}=0$, then estimates of $\alpha_{1}$ will vary randomly around zero and the tstatistics will not show any clear relationship with the degrees of freedom. By contrast, if we find that $\alpha_{1} \neq 0$, the observed magnitude of the t-statistics will vary with its degrees of freedom. This would provide evidence of a systematic effect, as we mention above. In our context, we are interested in the t-statistics for the coefficient associated with the variable of private production in a regression where the dependent variable is costs of producing the service. Where $\alpha_{1}=0$ in Equation (4), we have evidence that the genuine empirical effect is zero.

THE EMPIRICAL STRATEGY 
Our empirical analysis has two goals. First, we want to examine the influence of such characteristics as sample size, time-period, geographic area, and service characteristics on the findings from empirical studies of the relationship between private production, public production, and costs. Although a more complete model might also include measures of competition, market dynamics, transaction costs, and service quality, we are unable to measure these aspects with any degree of accuracy in our meta-regression because virtually none of the previous studies directly tested for these effects. Second, we want to analyze the cost effects of privatization and examine whether these effect are contaminated by possible publication bias.

The Sample of Studies

To the best of our knowledge, the sample used here includes all studies, both published and unpublished, that use multivariate regression techniques to examine the cost effects of privatizing the delivery of local solid waste collection or water distribution services. Our meta-regression includes articles published in academic journals in the fields of economics, political science, and public policy and public administration. Additionally, we have conducted an extensive search in relevant working paper series (such as the Social Science Research Network—SSRN).

All the studies in our sample are concerned with publicly provided services supplied either by municipalities (public production) or via government contracts with private firms (private production). All use the total or average costs of producing the service as their dependent variable, and production at the local level as their unit of analysis. Our explanatory variable of interest regarding costs is the form of service delivery (that is, public or private production).

Individual studies can provide more than one observation in our data if they contain several estimations containing different data sets or different explanatory variables. Table 1 provides a list of the 27 studies used in our analysis and their key differentiating characteristics including the t-statistics for the privatization variable, sample size, period of analysis, and the number of observations each study contributes to the sample (total observations $=46$ ). Note that the studies included in our analysis use local municipality data, have a cost variable for which we can use the t-statistic in our meta-regression, and involve cross-sectional data in a linear regression, log-linear regression, twostage estimation, or maximum likelihood analysis.

\section{Insert Table 1 about here}

The first econometric study of waste collection (Hirsch, 1965) used a production cost model that controlled for amount, quality, and service conditions that affect input requirements, factor prices, technology, density, and form of finance (user fee or general budget). Later studies used similar 
models (Collins \& Downes, 1977; Kempler \& Quigley, 1976), with variables that addressed features of property rights, transaction costs, and industrial organization theories. Stevens (1978) improved the model and paid greater attention to scale economies. Dubin and Navarro's (1988) model was the first to consider the choice of production and the comparison of costs jointly. Recent studies have used more comprehensive databases and more sophisticated econometric techniques. Cost savings were more frequent in the earlier studies (during the 1970s and 1980s), and less so in later studies.

The empirical literature on urban water distribution and costs dates back to the mid-1970s. Between the mid-1970s and the mid-1990s, econometric studies of this question were limited to the US. Mann and Mikesell (1976) and Morgan (1977) set up the basic model, focusing on operational costs, which was adopted in most subsequent studies. Feigenbaum and Teeples (1983) used a hedonic costs model, and Fox and Hofler (1986) introduced the multi-product characteristic (production and distribution) of water firms. Subsequent studies in the US followed this latter approach. Since 2000, the first econometric studies conducted outside the US and the UK have appeared, covering a wide and mixed set of geographical areas including Estonia and Latvia (Jones \& Mygind, 2000), Asia and the Pacific (Estache \& Rossi, 2002) and Africa (Kirkpatrick et al., 2006). Additional details on all these papers are found in Bel and Warner (2008).

Of the original 35 studies identified by Bel and Warner (2008), we excluded those that did not use an explicit cost variable and included three additional recent papers on solid waste collection (Bel \& Mur, 2009; Bel \& Fageda, in press; Bae, in press). For water, we excluded the works on the UK by Ashton (2000a, 2000b) and Saal and Parker (2000, 2001) because they examine efficiency using productivity data at the national level. Interestingly, they do not find significant efficiency improvements after privatization. We also excluded several studies that estimate a production function to obtain productivity or efficiency indicators, because their dependent variable is not consistent with our cost variable target. These works are Feigenbaum and Teeples (1983), Fox and Hofler (1986), Teeples and Glyer (1987), Link (1993), Bhattacharyya, Parker, and Raffie (1994), Bhattacharyya, Harris, Narayanan, and Raffie (1995), and Jones and Mygind (2000). None of these studies finds private production to be significantly less efficient than public production.

For solid waste, we excluded from our meta-regression analysis Szymanski's (1996) study in the UK because he jointly considers the effects on costs of public and private ownership and the use of a competitive tendering process. Szymanski (1996) finds both private and public ownership with competition are related to cost savings when compared to public production without competition. 
However, cost savings obtained from competition erode overtime, and they do so more quickly under public production than under private production.

Our analysis focuses on cross-sectional studies in which public and private production are compared. A better measure of the effects of privatization on costs would require the use of timeseries data to account for the change from public to private production with regard to the same unit of analysis. However, we were only able to identify seven studies (Domberger, Meadowcroft, \& Thompson, 1986; Lynk, 1993; Szymanski, 1996; Szymanski \& Wilkins, 1993; Reeves \& Barrow 2000; Dijkgraaf \& Gradus, 2007; Bae, in press) that used time-series data, and five of these (all but Lynk, 1993 and Szymanski, 1996) are included in our analysis. However, even these five studies did not measure the before and after effects of privatization within the same locality, but rather changes over time across localities.

From this descriptive review, we can see that some of the studies report significant cost savings from private production (see Table 1). However, we are not able to identify a systematic pattern in the relationship between private production and costs. If we look in detail at the t-statistics reported, about half of the studies find statistically significant costs savings with private production, while the remaining studies find an ambiguous or negative relationship between private production and costs. Note that most of the evidence for cost savings comes from the early studies conducted back in the 1970s. Since then, few studies report any cost savings from private production for solid waste, and only Raffie, Narayanan, Harris, Lambert, and Collin (1993) find cost savings for water distribution services. While private production may lead to cost reductions in some instances, these studies fail to provide a strong argument in favor of private production.

The Meta-regression Equation

The linear equation that we estimate to examine the influence of different study characteristics on reported results is as follows:

$$
T=\alpha+\beta_{1} \text { Sample_size }+\beta_{2} \text { Year }+\beta_{3} \text { Functional_form }+\beta_{4} \text { Service }+\beta_{5} U S+\beta_{6} U K+\beta_{7} \text { Panel }+\varepsilon
$$

where the dependent variable measures cost differences under public and private ownership. The dependent variable is the t-statistic $(T)$ of the dummy variable for private ownership in the corresponding estimated cost equation. Studies reporting lower privatization t-statistics suggest a less statistically significant or negative relationship between service costs and private production as compared to public production. This equation comes from Equation (2b), which was derived in the methodology section. 
Our parameter of interest, $T$, the dependent variable in Equation (5), is the t-statistic for the coefficient associated with the variable of private production in a regression where the dependent variable is total costs of producing the service. If the true effect is a systematic relationship between private production and lower costs, then that parameter should be negative and different from zero. To assess if it is different from zero, we must examine the statistical significance of the coefficient associated with sample size, $\beta_{1}$. Recall that the magnitude of the t-statistics will vary systematically with sample size only if there is in fact a systematic empirical effect.

Furthermore, Equation (5) will allow us to analyze the influence of study characteristics like year, method, type of service, or country on the t-statistics obtained (that is, on the estimated effect of private production on costs).

The explanatory variables of the meta-regression equation (Equation 5), sometimes also called moderator variables, concern particular characteristics of the empirical studies. A negative sign in the coefficient of an Equation 5 explanatory variable means that studies with a higher value of this variable are more likely to find cost savings from private production (that is, it increases the likelihood of finding negative t-statistics or lower positive t-statistics). A positive sign means that a higher value of this variable makes cost savings less likely.

A common meta-regression moderator variable is the number of observations in the analyses included in each study, Sample_size, as studies with larger numbers of observations are considered more robust. Indeed, the estimated effects of the parameter of interest (for example, the effect of privatization on cost savings) are expected to be closer to their true effects for larger sample sizes. If the sample size variable is negative and significant then we have some evidence of lower costs under private production. ${ }^{6}$ Given that one of the contributions of the meta-regression is to provide evidence about the genuine empirical effect of the relationship between private production and costs, we conduct several tests to obtain further insights into this question.

Another moderator variable commonly used in meta-regression analysis is the year in which the data were collected, Year. We are interested in examining whether recent studies find smaller differences between public and private ownership than was the case in earlier studies. Recent studies may, for example, capture rising costs among private producers (Ohlsson, 2003), the potential for collusion (Dijkgraaf \& Gradus, 2007), or efficiency gains under public production (Bel \& Costas,

${ }^{6}$ Indeed, this would imply that studies with larger sample sizes (whose results should be closer to the true effect) are obtaining larger negative t-statistics for the coefficient associated with the variable of private production in the cost equation, and larger negative t-statistics for that coefficient would lead to the conclusion of systematic lower costs with private production. 
2006). However, we cannot make any strong claims regarding dynamics over time because almost all of the studies in our analysis are cross sectional.

We also account for the role of functional form in explaining variation in the reported results across studies by using a dummy variable, Functional_form, that takes the value one when the linear form is used, and zero in other cases (usually the double-log form). This is another common moderator variable used in meta-regression analyses. However, we do not expect substantial differences in results from our sample of studies due to the choice of functional form. This choice might influence the estimated magnitude of the relationship between private production and costs but not necessarily its statistical significance.

Aggregating studies for solid waste collection and water distribution could result in some estimation bias as the estimates refer to two different services. We include a dummy variable that takes the value of one for solid waste collection and zero for water distribution. We also estimate Equation (5) for the sub-sample of studies that analyze solid waste collection. Eighty percent of the studies cover solid waste. By looking at the sub-sample of studies on solid waste collection, we can examine the influence of different characteristics avoiding any distorting effect derived from jointly considering services with very different cost structures. A distinctive characteristic of water is the high transaction costs associated with its delivery. We cannot estimate Equation (5) for the subsample of water distribution studies because the subsample is not large enough, and thus we are not able to isolate the services with high transaction costs.

We also include moderator variables for the geographic area analyzed. We include two dummy variables that take the value of one when the study refers to United States (US) or the United Kingdom (UK), respectively. These two countries account for the highest number of observations in our sample of studies, and are the countries in which these reforms in local public services have been most widely tested. Note that both countries are characterized by a competitive market framework in the delivery of local services relative to other countries. Public units in these countries often actively participate in competitive bidding in their own and neighboring municipalities. In addition, many local governments in the US mix both public and private production within their jurisdiction as a way to encourage competition (Miranda \& Lerner, 1995; Warner \& Hefetz, 2008).

The quality of data used in a cross-sectional analysis may not be as strong as in a longitudinal analysis, so we include a moderator variable that captures this aspect of data quality. The dummy variable, panel, takes the value of one for longitudinal studies. 
Variables for the intensity of competition or other institutional features aside from type of ownership would provide additional insights, but measures of these are found only in the studies by Bel and Costas (2006) and Dijkgraaf and Gradus (2007). It would be interesting to examine the influence of the multi-product nature of the services analyzed, but most of the studies do not account for multi-product effects. Note that while we present the current state of knowledge in the theoretical background (which is cumulative), only the most recent studies (after 2005) reflect the current propositions regarding transaction costs, competition, or market characteristics. Thus, we lack enough data to consider these as moderators in our meta-regression.

Results of the Meta-regression Equation

Table 2 presents descriptive statistics for the variables included in the meta-regression equation. The mean t-statistic is negative indicating that private production typically results in lower costs than public production, but there is considerable dispersion in the value of the t-statistic. Hence, these data suggest there may not be significant cost differences between public and private production. Our sample of studies covers estimations made for the period 1960 to 2005 . $^{7}$

\section{Insert Table 2 about here}

Table 3 shows the results from the estimation of the meta-regression equation (Equation (5)) that comes from Equation (2b) in the methodology section. The estimation is made both for all studies and for the studies that focus on solid waste. Recall that the statistical significance of the coefficient of the variable for sample size will allow us to examine the underlying empirical effect in the relationship between privatization and costs. Additionally, the statistical significance of the coefficients associated with the variables of year, methods, service, or country will allow us to examine the influence of these study characteristics on the reported results of the relationship between private production and costs.

Note that some of the studies contribute more than one observation to the sample because they include different estimations with different data sets or different explanatory variables. To correct for possible violation of the uncorrelated errors assumptions between observations from the same study, we adjust our estimates by clustering observations from the same study.

\section{Insert Table 3 about here}

Importantly, the coefficient of the variable for Sample Size is negative but not statistically significant. This means that larger sample studies are not more likely to report cost savings from

\footnotetext{
7 When a study uses a data set with a cross-section and time-series form, we compute the first year of the period for the moderator variable, year.
} 
private production. That is, they are not more likely to find larger negative t-statistics for the coefficient associated with the variable of private production in their cost equation. The magnitude of the t-statistics will vary systematically with sample size only if there is in fact a systematic empirical effect. In other words, results of studies with larger sample sizes should be closer to true effect. Thus, we do not find clear evidence that the true effect is a systematic relationship between private production and costs.

From the result for the variable of sample size, we conclude there is no statistical support for an empirical effect of private production on costs. This is true for studies that analyze solid waste collection and water distribution and studies that only analyze solid waste collection. In the following sub-section, we implement several tests that confirm this result.

The coefficient for the variable Year has a positive sign and is statistically significant. This means more recent studies are less likely to find cost differences between public and private production. This is true for studies that analyze solid waste collection and water distribution and studies that only analyze solid waste collection.

The coefficient functional form is not statistically significant; functional form does not explain why some studies find cost savings and others do not. The coefficient of the dummy variable for services is negative although its statistical significance is modest. This provides some evidence that lower costs under private production are more likely in solid waste collection than they are in water distribution. This may be explained by differences in transaction costs. Privatizing water distribution involves higher transaction costs for local governments; whereas, privatizing the delivery of solid waste collection may allow for exploitation of scale economies. ${ }^{8}$

Our geographic variable shows the US studies are less likely to find differences between public and private production in both the full sample meta-regression estimation and the solid waste only estimations. Finally, the coefficient of the dummy variable for longitudinal studies is negative and significant. Thus, studies that use a data set with a cross-section and time-series form seem to find more differences between public and private production. However, these studies did not measure the before and after effects of privatization but rather changes over time across localities.

\footnotetext{
8 Privatization can facilitate scale economies because private companies can distribute fixed costs efficiently over several geographic units, as they are not constrained to a single municipality (Bel \& Miralles, 2003). Several studies have found evidence of scale economies in solid waste collection (Stevens, 1978; Callan \& Thomas, 2001; Bel \& Costas, 2006; Bel \& Fageda, in press), but scale economies are exhausted as population increases. Inter-municipal cooperation is another alternative for promoting scale economies.
} 
Results of the Meta-regression Tests

As we mention above, publication bias is a major concern of meta-regression analysis because papers are more likely to be published when significant relationships between the variables of interest are found (Stanley, 2005b; 2007). In our context, the direction of the bias is likely to be as follows: Devotees of contracting uncover statistically significant savings (significant negative t-statistics), while detractors might be satisfied with no savings, rather than finding that diseconomies are statistically significant. ${ }^{9}$ As a result, the empirical literature that compares the performance of public and private production may find larger cost differences than those related to the true effect of privatization.

Table 4 shows results of funnel asymmetry tests (FAT) using both the inverse of standard errors (column 1) and the square roots of the sample size (column 2) as independent variables, and results of the meta-significance test (MST) are indicated in column 3.

Recall that the FAT test estimates the relationship between a study's reported effect and the standard errors of its coefficients (or the square root of sample size). The FAT test comes from Equation (3a) in the methodology section. We will find evidence of publication bias if the intercept term is different from zero. Additionally, we will find evidence of a true empirical effect (that is, a systematic relationship between private production and costs) if the coefficient associated with the inverse of the standard error (or the square root of sample size) is different from zero. Additionally, the MST estimates the relationship between a study's t-statistic and its degrees of freedom using the logarithmic form. The MST test comes from Equation (4) in the methodology section. We will find evidence of a true empirical effect in the relationship between private production and costs if the coefficient associated with degrees of freedom is different from zero.

We do not find any evidence of a genuine empirical effect in the relationship between private production and costs because our estimates show that the coefficients associated with the inverse of the standard errors (column 1), the square root of sample size (column 2) or the logarithm of degrees of freedom (column 3) are not statistically different from zero. Hence, our analysis provides empirical evidence that private production of local services is not systematically less costly than that of public production.

\section{Insert Table 4 about here}

\footnotetext{
${ }^{9}$ We thank one of the anonymous referees for this insight.
} 
Table 4 presents mixed evidence of publication bias. The FAT test shows that the intercept term is statistically different from zero when using the inverse of the standard error as an independent variable (column 1). However, this intercept term is not significant when using the square root of the sample size (column 2). Recall that the inverse of the standard errors may have measurement errors that the square root of the sample size does not have. Hence, we should be more confident with the results of the estimation using the square root of the sample size as the independent variable. If there is publication bias, the direction is negative as expected; the studies are obtaining overly large cost savings - negative t-statistics — of private production from a statistical point of view. This evidence of publication bias, somewhat equivocal as it is, strengthens our finding that a strong association between cost savings and private production is not justified.

Concerning the explanatory variables of the meta-regression, publication bias may be filtered by estimating a multivariate FAT-meta-regression model (Stanley, 2005b). The multivariate FAT-meta regression model comes from Equation (3b) in the methodology section. In practice, this will imply re-estimating Equation (5) to include the inverse of standard errors or the square root of sample size instead of sample size as the independent variable. This allows us to test whether publication bias distorts our results in relation to the other study characteristics we use as explanatory variables. In addition, this provides additional tests of publication bias. The estimated effects should vary randomly around the true value if publication bias is absent, and this will be the case if the intercept term of the FAT-meta-regression model is not statistically significant. Additionally, the FAT-metaregression model includes other explanatory variables (for example, study characteristics) that may influence the reported effects. This enables us to obtain results for these explanatory variables given the value of the intercept term that measures any possible publication bias.

Table 5 shows the results of these estimates. Our previous results in relation to the moderator variables in Equation (1) are confirmed since the sign and statistical significance of each explanatory variable does not change with the new estimation. In fact, the variable, service, is now statistically significant at the 10 percent level (not just at the 11 percent level) when using the inverse of standard errors as an explanatory variable. Furthermore, we find stronger evidence of publication bias-that the empirical literature comparing the performance of public and private production may find larger negative $t$-statistics than those related to the true effect of privatization.

\section{Insert Table 5 about here}




\section{CONCLUSION}

The advantage of a meta-regression analysis is that it allows us to determine the overall impact of phenomena across a wide range of studies. Previous narrative meta-analyses of cost differences between public and private production have reported mixed findings (Boyne, 1998; Hirsch, 1995; Hodge, 2000; Bel \& Warner, 2008). Our meta-regression analysis allows us to determine the impact of certain variables that account for these differences across studies.

In the studies we examine, the average t-statistic for privatization is negative, implying lower costs on average for private production. However, this result does not hold up in the more rigorous meta-regression analysis once we have controlled for sample size and other factors. Indeed, our results can be seen as another warning that studies conducted with small sample sizes be interpreted with caution. Moreover, we find some evidence of publication bias, which means that papers obtaining significant cost savings are more likely to be published. We also find cost differences to be less likely in more recent studies. As expected, cost savings are more likely in solid waste collection than in water distribution services given the lack of competition and higher asset specificity of the latter. Our results also show that lower costs are dependent on service characteristics, geographic area, and time-period of the study. Transaction costs are of significance in that they are responsible for the greater likelihood of savings for solid waste collection than for water distribution. Many public services are natural monopolies with high asset specificity, as in the case of water distribution, and private production in these cases is unlikely to yield cost savings.

The major theoretical approaches to privatization suggest that competition can have a positive effect on cost savings. Unfortunately, our meta-regression analysis is unable to capture properly the impact of competition on cost differences between private and public production. Our results indicate that the more competitive policy environment in the US in comparison to that in other countries reduces the likelihood of finding cost savings with private production. It could well be that the primary benefit from opening up competition for public services is the efficiency improvements this generates among public producers as a result of benchmarking pressure from potential private competition.

Public choice, property rights, transaction costs, and industrial organization approaches all contribute to our understanding of privatization, but individually each one only captures part of the costs and service delivery equation. Competition, market dynamics, transactions costs, and service quality are also important, but the existing empirical evidence does not allow us to understand their impact fully. Policymakers should pay careful attention to these factors when considering the choice 
between public or private production. Future empirical analyses should give increased emphasis to the characteristics of the service (potential for technological improvement, sunk costs), the characteristics of the contract (specification and monitoring, transaction costs), the characteristics of the market (competition), and the managerial and policy environment. These are the priorities for future research. 


\section{References}

Ashton, J. K. (2000a). Cost efficiency in the UK water and sewerage industry. Applied Economics Letters, 7, 455-458.

Ashton, J. K. (2000b). Total factor productivity growth and technical change in the water and sewerage industry. Service Industries Journal, 20, 121-130.

Bae, S. (in press). Public versus private delivery of municipal solid waste services: The case of North Carolina. Contemporary Economic Policy.

Bel, G. (2006). Economía y política de la privatización local. Madrid: Marcial Pons.

Bel, G., \& Costas, A. (2006). Do public sector reforms get rusty? Local privatization in Spain. Journal of Policy Reform, 9, 1-24.

Bel, G., \& Fageda, X. (2007). Why do local governments privatize public services? A survey of empirical studies. Local Government Studies, 33, 517-534.

Bel, G., \& Fageda, X. (2008). Reforming the local public sector: Economics and politics in privatization of water and solid waste. Journal of Economic Policy Reform, 11, 45-65.

Bel, G., \& Fageda, X. (2009). Factors explaining local privatization: A meta-regression analysis. Public Choice, 139, 105-119.

Bel, G., \& Fageda, X. (in press). Empirical analysis of solid management waste costs: Some evidence from Galicia, Spain. Resources, Conservation and Recycling.

Bel, G., \& Miralles, A. (2003). Factors influencing privatisation of urban solid waste collection in Spain, Urban Studies, 40, 1323-1334.

Bel, G., \& Mur, M. (2009). Intermunicipal cooperation, privatization and waste management costs: Evidence from rural municipalities, Waste Management, 29, 2772-2778.

Bel, G., \& Warner, M. (2008). Does privatization of solid waste and water services reduce costs? A review of empirical studies. Resources, Conservation and Recycling, 52, 1337-1348.

Bhattacharyya, A., Parker, E., \& Raffie, K. (1994). An examination of the effect of ownership on the relative efficiency of public and private water utilities. Land Economics, 70, 197-209.

Bhattacharyya, A., Harris, T. R, Narayanan, R., \& Raffie, K. (1995). Specification and estimation of the effect of ownership on the economic efficiency of water utilities. Regional Science and Urban Economics, 25, 759-784.

Bolton, P., \& Dewatripont, M. (2005). Contract theory. Cambridge, MA: MIT Press.

Boyne, G. A. (1998). Bureaucratic theory meets reality: Public choice and service contracting in US local government. Public Administration Review, 58, 474-484.

Bozeman, B. (1987). All organizations are public: Bridging public and private organizational theories. San Francisco, CA: Jossey Bass.

Brown, T. L., \& Potoski, M. (2003). Managing contract performance: A transaction cost approach. Journal of Policy Analysis and Management, 22, 275-297. 
Brown, T. L., \& Potoski, M. (2005). Transaction costs and contracting: The practitioner perspective. Public Performance \& Management Review, 28, 326-351.

Bruggink, T. H. (1982). Public versus regulated private enterprise in the municipal water industry: A comparison of operating costs. Quarterly Review of Economics and Business, 22, 111-125.

Byrnes, P. (1991). Estimation of cost frontiers in the presence of selectivity bias: Ownership and efficiency of water utilities. Advances in Econometrics, 9, 121-137.

Callan, S. J., \& Thomas, J. M. (2001). Economies of scale and scope: A cost analysis of municipal solid waste services. Land Economics, 77, 548-560.

Card, D., \&Krueger A. B. (1995). Time-series minimum wage studies: A meta-analysis. American Economic Review, 85, 238-243.

Coase, R. H. (1937). The nature of the firm. Economica, 4, 386-405.

Collins, J. N., \& Downes, B. T. (1977). The effect of size on provision of public services: The case of solid waste collection in smaller cities. Urban Affairs Quarterly, 12, 333-347.

Connor, J. M., \& Bolotova, Y. (2006). Cartel overcharges: Survey and meta-analysis. International Journal of Industrial Organization, 24, 1109-1137.

Crain, W. M., \& Zardkoohi, A. (1978). A test of the property-rights theory of the firm: Water utilities in the United States. Journal of Law and Economics, 21, 395-408.

Davies, S. (2007). Politics and markets: The case of UK municipal waste management. (Working Paper \#95) Cardiff, Wales, UK: School of Social Sciences, Cardiff University.

Dijkgraaf, E., \& Gradus, R. H. J. M. (2003). Cost savings of contracting out refuse collection. Empirica, 30, 149-161.

Dijkgraaf, E., \& Gradus, R. H. J. M. (2007). Collusion in the Dutch waste collection market. Local Government Studies, 33, 573-588.

Dijkgraaf, E., \& Gradus, R. H. J. M. (2008). Institutional developments in the Dutch waste collection market. Government \& Policy, 26, 110-126.

Dnes, A.W. (1995). Franchising and privatization. Washington DC: The World Bank.

Domberger, S., Meadowcroft, S. A., \& Thompson, D. J. (1986). Competitive tendering and efficiency: The case of refuse collection. Fiscal Studies, 7 (4), 69-87.

Donahue, J. D. (1989). The privatization decision. Public ends, private means. New York, NY: Basic Books.

Dubin, J. A, \& Navarro, P. (1988). How markets for impure public goods organize: The case of household refuse collection. Journal of Law, Economics \& Organization, 4, 217-241.

Eggers, W. D., \& O'Leary, J. (1995). Revolution at the roots: Making our government smaller, better, and closer to home. New York, NY: The Free Press.

Estache, A., \& Rossi, M. A. (2002). How different is the efficiency of public and private water companies in Asia? World Bank Economic Review, 16, 139-148.

Feigenbaum, S., \& Teeples, R. (1983). Public versus private water delivery: A hedonic cost approach. Review 
of Economics and Statistics, 65, 672-678.

Ferris, J., \& Graddy, E. (1994). Organizational choices for public service supply. Journal of Law, Economics \& Organization, 10, 126-141.

Fox, W. F., \& Hofler, R. A. (1986). Using homothetic composed error frontiers to measure water utility efficiency. Southern Economic Journal, 53, 461-477.

Geys, B. (2006). Explaining voter turnout: A review of aggregate-level research. Electoral Studies, 25, 637663.

Görg, H, \& Strobl, E. (2001). Multinational companies and productivity spillovers: A meta-analysis. Economic Journal, 111, 723-740.

Grossman, S.J., \& Hart, O. D. (1986). The costs and benefits of ownership: A theory of vertical and lateral integration. Journal of Political Economy, 94, 691-719.

Guttman, D. (2000). Public purpose and private service: The twentieth century culture of contacting out and the evolving law of diffused sovereignty. Administrative Law Review, 52, 859-926.

Hart, O. D., \& Moore, J. (1990). Property rights and the nature of the firm. Journal of Political Economy, 98, $1119-1158$.

Hart, O. D., Shleifer, A., \& Vishny, R. W. (1997). The proper scope of government: Theory and an application to prisons. Quarterly Journal of Economics, 112, 1127-1161.

Hatry, H. P. (1988). Privatization presents problems. National Civic Review, 77, 112-117.

Hefetz, A., \& Warner, M. E (2004). Privatization and its reverse: Explaining the dynamics of the government contracting process. Journal of Public Administration, Research and Theory, 14, 171-190.

Hefetz, A., \& Warner, M. E (2007). Beyond the market vs. planning dichotomy: Understanding privatisation and its reverse in US cities. Local Government Studies, 33, 555-572.

Hirsch, W.Z. (1965). Cost functions of an urban government service: refuse collection. Review of Economics and Statistics, 47, 87-92.

Hirsch, W. Z. (1995). Contracting out by urban governments: A review. Urban Affairs Review, 30, 458-472.

Hodge, G. (2000). Privatization. An international review of performance. Boulder, CO: Westview Press.

Jones, D. C., \& Mygind, N. (2000). The effects of privatization on productive efficiency: Evidence from the Baltic republics. Annals of Public and Cooperative Economics, 71, 415-439.

Kavanagh, I., \& Parker, D. (1999). Managing the contract: A transaction cost analysis of externalisation. Local Government Studies, 26, 1-22.

Kay, J. A., \& Thompson, D. J. (1986). Privatisation: A policy in search of a rationale. Economic Journal, 96, $18-32$.

Kemper, P., \& Quigley, J. (1976). The economics of refuse collection. Cambridge, MA: Ballinger.

Kirkpatrick, C., Parker, D., \& Zhang, Y. Z. (2006). State versus private sector provision of water services in Africa. World Bank Economic Review, 20, 143-163.

Kitchen, H. M. (1976). A statistical estimation of an operating cost function for municipal refuse collection. Public Finance Quarterly, 4, 56-76. 
Laffont, J. J., \& Tirole, J. (1993). A theory of incentives in procurement and regulation. Cambridge (MA): MIT Press.

Levin, J., \& Tadelis, S. (in press). Contracting for government services: theory and evidence from U.S. cities, Journal of Industrial Economics.

Longhi, S., Nijkamp, P., \& Poot, J. (2005). A meta analytic assessment of the effect of immigration on wages. Journal of Economic Surveys, 19, 451-477.

Lowery, D. (1998). Consumer sovereignty and quasi-market failure. Journal of Public Administration Research and Theory, 8, 137-172.

Lynk, E. L. (1993). Privatisation, joint production and the comparative efficiency of private and public ownership: The UK water industry case. Fiscal Studies, 14 (2), 98-116.

Mann, P. C., \& Mikesell, J. L. (1976). Ownership and water system operation. Water Resources Bulletin, 12, 995-1004.

Melo, P. C, Graham, D. J., \& Noland, R. B. (2009). A meta-analysis of estimates of urban agglomeration economies. Regional Science and Urban Economics, 39, 332-342.

Miranda, R., \& Lerner, A. (1995). Bureaucracy, organizational redundancy, and the privatization of public services. Public Administration Review, 55 , 193-200.

Morgan, W. D. (1977). Investor owned vs. publicly owned water agencies: An evaluation of the property rights theory of the firm. Water Resources Bulletin, 13, 775-781.

Mrozek, J. R., \& Taylor, L. O. (2002). What determines the value of life? A meta-analysis. Journal of Policy Analysis and Management, 21, 253-270.

Niskanen, W. A. (1971). Bureaucracy and representative government. Chicago, Il: Aldine.

Nelson, M. A. (1997). Municipal government approaches to service delivery: An analysis from a transactions cost perspective. Economic Inquiry, 35, 82-96.

Ohlsson, H. (2003). Ownership and production costs. Choosing between public production and contractingout in the case of Swedish refuse collection. Fiscal Studies, 24 (4), 451-476.

Osborne, D., \& Gaebler, T. (1992). Reinventing government: How the entrepreneurial spirit is transforming government. Reading, MA: Addison-Wesley.

Osborne, D., \& Plastrick, P. (1997). Banishing bureaucracy. Reading, MA: Addison-Wesley.

Pommerehne, W. W., \& Frey, B. (1977). Public versus private production efficiency in Switzerland: A theoretical and empirical comparison. Urban Affairs Annual Review, 12, 221-241.

Raffie, K., Narayanan, R., Harris, T. R., Lambert, D., \& Collins, J. M. (1993). Cost analysis of water utilities: A goodness-of-fit approach. Atlantic Economic Journal, 21 (3), 18-29.

Ringquist, E. J. (2005). Assessing evidence of environmental inequities: A meta-analysis. Journal of Policy Analysis and Management, 24, 223-247.

Reeves, E., \& Barrow, M. (2000). The impact of contracting-out on the costs of refuse collection services. The case of Ireland. Economic and Social Review, 31, 129-150. 
Saal, D. S., \& Parker, D. (2000). The impact of privatization and regulation on the water and sewerage industry in England and Wales: A translog cost function model. Managerial and Decision Economics, 21, 253-268.

Saal, D. S., \& Parker, D. (2001). Productivity and price performance in the privatized water and sewerage companies of England and Wales. Journal of Regulatory Economics, 20, 61-90.

Sappington, D. E. M., \& Stiglitz, J. E. (1987). Privatization, information and incentives. Journal of Policy Analysis and Management, 6, 567-582.

Savas, E. S. (1987). Privatization. The key to better government. Chatham, NJ: Chatham House.

Sclar, E. (2000). You don't always get what you pay for. The economics of privatization. Ithaca, NY: Cornell University Press.

Shleifer, A. (1998). State versus private ownership. Journal of Economic Perspectives. 12 (4), 133-150.

Shleifer, A., \& Vishny, R. W. (1994). Politicians and firms. Quarterly Journal of Economics, 109, 995-1025.

Smith, V. K, \& Huang, J. C. (1995). Can markets value air quality? A meta-analyses of hedonic property value models. Journal of Political Economy, 103, 209-227.

Stanley, T. D. (2005a). Integrating the empirical tests of the natural rate hypothesis: A meta-regression analysis. Kyklos, 58, 611-634

Stanley, T. D. (2005b). Beyond publication bias. Journal of Economic Surveys, 19, 309-345.

Stanley, T. D. (2007). Meta-regression methods for detecting and estimating empirical effects in the presence of publication selection. Oxford Bulletin of Economics and statistics, 70, 103-127.

Stanley, T. D., \& Jarrell, S. B. (1989). Meta-regression analysis: A quantitative method of literature surveys. Journal of Economic Surveys, 3, 54-67.

Stein, R. M. (1990). Urban alternatives: Public and private markets in the provision of local services. Pittsburgh, PA: University of Pittsburgh Press.

Stevens, B. J. (1978). Scale, market structure, and the cost of refuse collection. Review of Economics and Statistics, 60, 438-448.

Szymanski, S. (1996). The Impact of compulsory competitive tendering on refuse collection services. Fiscal Studies, 17 (3), 1-19.

Szymanski, S., \& Wilkins, S. (1993). Cheap rubbish? Competitive tendering and contracting out in refuse collection. Fiscal Studies, 14 (3), 109-130.

Teeples, R., \& Glyer, D. (1987). Cost of water delivery systems: Specifications and ownership effects. Review of Economics and Statistics, 69, 399-408.

Tickner G., \& McDavid, J. C. (1986). Effects of scale and market structure on the costs of residential solid waste collection in Canadian cities. Public Finance Quarterly, 14, 371-393.

Tiebout, C. (1956). A pure theory of local public expenditures. Journal of Political Economy, 64, 416-424.

Vickers, J., \& Yarrow, G. (1988). Privatization: An economic analysis. Cambridge, MA: MIT Press. 
Warner, M. E., \& Bel, G. (2008). Competition or monopoly? Comparing US and Spanish privatization. Public Administration: An International Quarterly, 86, 723-735.

Warner, M. E., \& Hebdon, R. (2001). Local government restructuring: Privatization and its alternatives. Journal of Policy Analysis and Management, 20, 315-336.

Warner, M. E., \& Hefetz, A. (2008). Managing markets for public service: The role of mixed public/private delivery of city services. Public Administration Review, 68, 150-161.

Warner, M. E. \& Hefetz, A. (in press). Service characteristics and contracting: The importance of citizen interest and competition. In The municipal year book 2010. Washington, DC: International City County Management Association.

Williamson, O. E. (1999). Public and private bureaucracies: A transaction cost economics perspective. Journal of Law, Economics, \& Organization, 15, 306-342. 
Table 1. Characteristics of Studies Included in the Meta-Regression Analysis

\begin{tabular}{|c|c|c|c|c|c|c|c|}
\hline Study & $\begin{array}{l}\text { T-statistic } \\
\text { (Cost savings } \\
\text { from private } \\
\text { production) }\end{array}$ & $\begin{array}{l}\text { Sample } \\
\text { size }\end{array}$ & \begin{tabular}{|c} 
Year \\
(data \\
collection \\
)
\end{tabular} & Country & Regression method & \begin{tabular}{|c|} 
Number \\
estimations
\end{tabular} & Service \\
\hline Hirsch (1965) & -0.8 & 24 & 1960 & USA & Linear regression & 1 & Solid waste \\
\hline Kitchen (1976) & $-7.4^{+}$ & 48 & 1970 & Canada & Linear regression & 1 & Solid waste \\
\hline Kemper \& Quigley (1976) & $-1.7 /-10.7^{+}$ & $15 / 57$ & 1972-74 & USA & Linear regression & 4 & Solid waste \\
\hline Man \& Mikesell (1976) & 1.9 & 214 & 1976 & USA & Linear regression & 1 & Water \\
\hline Collins \& Downes (1977) & 1.5 & 53 & 1970 & USA & $\begin{array}{c}\text { Linear regression } \\
\text { Step-wise estimation }\end{array}$ & 1 & Solid waste \\
\hline Pommerehne \& Frey (1977) & $-2.8 /-4.2^{+}$ & 103 & 1970 & Switzer. & $\begin{array}{l}\text { Linear regression \& } \\
\text { Log-linear regression }\end{array}$ & 2 & Solid waste \\
\hline Morgan (1977) & $-2.3^{+}$ & 143 & 1970 & USA & Linear regression & 1 & Water \\
\hline Stevens (1978) & $-0.9 /-2.28^{+}$ & $55 / 112$ & 1974 & USA & Log-linear regression & 4 & Solid waste \\
\hline Crain \& Zardkoohi (1978) & $-2.3^{+}$ & 112 & 1970 & USA & Log-linear regression & 1 & Water \\
\hline Bruggink (1982) & 1.6 & 86 & 1960 & USA & Log-linear regression & 1 & Water \\
\hline Tickner \& McDavid (1986) & $-3.6^{+}$ & 132 & 1981 & Canada & Log-linear regression & 1 & Solid waste \\
\hline Domberger et al. (1986) & $-5.9^{+}$ & 610 & $1983-85$ & UK & $\begin{array}{l}\text { Log-linear regression } \\
\text { Panel estimation }\end{array}$ & 1 & Solid waste \\
\hline Dubin \& Navarro (1988) & -0.5 & 261 & 1974 & USA & $\begin{array}{l}\text { Linear regression } \\
\text { (control selectivity } \\
\text { bias) }\end{array}$ & 1 & Solid waste \\
\hline Byrnes (1991) & 0.6 & 154 & 1976 & USA & $\begin{array}{c}\text { Log-linear regression } \\
\text { Two stages } \\
\text { (correcting for } \\
\text { selectivity bias) }\end{array}$ & 1 & Water \\
\hline Szymanski \& Wilkins (1993) & $-1.7 /-2.7^{+}$ & $165 / 335$ & $1984-88$ & UK & $\begin{array}{l}\text { Log-linear regression } \\
\text { Two stage estimation }\end{array}$ & 5 & Solid waste \\
\hline Raffie et al. (1993) & $-2.9^{+}$ & 271 & 1989 & USA & Log-linear regression & 1 & Water \\
\hline Reeves \& Barrow (2000) & $-2.7 /-5.4^{+}$ & $48 / 144$ & 1993-1995 & Ireland & $\begin{array}{c}\text { Log-linear regression } \\
\text { Panel \& OLS } \\
\text { estimation }\end{array}$ & 4 & Solid waste \\
\hline Callan \& Thomas (2001) & $1.4 / 0.96$ & 110 & 1997 & USA & Linear regression & 2 & Solid waste \\
\hline Estache \& Rossi (2002) & 0.0 & 50 & 1995 & $\begin{array}{l}\text { Asia \& } \\
\text { Pacific }\end{array}$ & $\begin{array}{l}\text { Log-linear regression } \\
\text { OLS, OLS corrected } \\
\text { \& maximum } \\
\text { likelihood }\end{array}$ & 1 & Water \\
\hline Dijkgraaf \& Gradus (2003) & $-2.2^{+}$ & 85 & 1996-97 & Holland & Log-linear regression & 1 & Solid waste \\
\hline Ohlsson (2003) & 1.4 & 115 & 1989 & Sweden & Log-linear regression & 1 & Solid waste \\
\hline Bel \& Costas (2006) & $0.7 /-0.10$ & $39 / 186$ & 2000 & Spain & Log-linear regression & 4 & Solid waste \\
\hline Kirkpatrick et al (2006) & 2.0 & 76 & 2000 & Africa & $\begin{array}{l}\text { Log-linear regression, } \\
\text { maximum likelihood }\end{array}$ & 1 & Water \\
\hline Dijkgraaf \& Gradus (2007) & $-2.3^{+}$ & 491 & 1998-2005 & Holland & $\begin{array}{l}\text { Log-linear regression } \\
\text { Panel estimation }\end{array}$ & 1 & Solid waste \\
\hline Bel \& Mur (2009) & -0.6 & 56 & 2003 & Spain & Log-linear regression & 1 & Solid waste \\
\hline Bel \& Fageda (in press) & $1.94 / 1.33$ & 65 & 2005 & Spain & Log-linear regression & 2 & Solid waste \\
\hline Bae (in press) & -0.93 & 252 & $1997-2003$ & US & Translog regression & 1 & Solid Waste \\
\hline
\end{tabular}

Note: In the column of t-statistics, the superindex ${ }^{+}$marks those studies in which at least one of the estimations finds lower costs with private production with a statistical significance below 10 percent. 
Table 2. Summary statistics

\begin{tabular}{|c|c|c|c|c|}
\hline Continuous Variables & Mean & $\begin{array}{l}\text { Standard } \\
\text { Deviation }\end{array}$ & $\begin{array}{c}\text { Minimum } \\
\text { Value }\end{array}$ & $\begin{array}{c}\text { Maximum } \\
\text { Value }\end{array}$ \\
\hline T-statistic & -1.49 & 2.60 & -10.70 & 2 \\
\hline Sample_size & 140.15 & 125.07 & 15 & 610 \\
\hline Year & 1984.56 & 12.89 & 1960 & 2005 \\
\hline Discrete variables & \multicolumn{4}{|c|}{ Number of observations (total $=46$ ) } \\
\hline & \multicolumn{2}{|c|}{ Variable $=1$} & \multicolumn{2}{|c|}{ Variable $=0$} \\
\hline $\begin{array}{c}\text { Functional_form }(1=\text { linear, } \\
0=\text { other })\end{array}$ & \multicolumn{2}{|c|}{15} & \multicolumn{2}{|c|}{31} \\
\hline $\begin{array}{c}\text { Service }(1=\text { Solid waste, } \\
0=\text { water })\end{array}$ & \multicolumn{2}{|c|}{38} & \multicolumn{2}{|c|}{8} \\
\hline Panel & \multicolumn{2}{|c|}{5} & \multicolumn{2}{|c|}{41} \\
\hline USA & \multicolumn{2}{|c|}{25} & \multicolumn{2}{|c|}{21} \\
\hline UK & \multicolumn{2}{|c|}{9} & \multicolumn{2}{|c|}{37} \\
\hline Other countries & \multicolumn{2}{|c|}{13} & \multicolumn{2}{|c|}{33} \\
\hline
\end{tabular}

Table 3. Meta-regression estimates (OLS)

\begin{tabular}{|c|c|c|}
\hline Moderator variables & \multicolumn{2}{|c|}{$\begin{array}{c}\text { Dependent variable: Cost differences between public and private } \\
\text { production (t-statistic) }\end{array}$} \\
\hline & Full Sample & Studies for solid waste \\
\hline Sample_size & $-0.0022(0.0034)$ & $-0.0010(0.0033)$ \\
\hline Year & $0.11(0.032)^{* * *}$ & $0.14(0.028)^{* * *}$ \\
\hline Functional_form & $-0.61(1.08)$ & $0.0046(1.24)$ \\
\hline Service & $-1.60(0.96)$ & - \\
\hline USA & $1.90(0.90)^{* *}$ & $1.19(0.98)$ \\
\hline UK & $1.11(0.89)$ & $-2.79(0.73)^{* * *}$ \\
\hline Panel & $-2.62(0.70)^{* * *}$ & $-283.08(61.48)^{* * *}$ \\
\hline Intercept & $-227.38(64.09)^{* * *}$ & 0.37 \\
\hline $\mathrm{R}^{2}$ & 0.34 & $7.31^{* * *}$ \\
\hline F (joint sig.) & $6.81^{* * *}$ & 37 \\
\hline $\mathrm{N}$ & 46 & (t) \\
\hline
\end{tabular}

Note 1: Standard errors in parentheses (robust to heteroskedasticity and adjusted by correlation between observations in the same study).

Note 2: Significance at the 1 percent $\left({ }^{* *}\right), 5$ percent $(* *), 10$ percent $\left(^{*}\right)$ level.

Note 3: The variable of service is significant at the 11 percent level in the estimation that considers the full sample. 
Table 4. Meta-regression tests (OLS)

\begin{tabular}{|c|c|c|c|}
\hline & $\begin{array}{c}\text { FAT (1) } \\
\text { Dep variable: t- } \\
\text { statistic }\end{array}$ & $\begin{array}{c}\text { FAT (2) } \\
\text { Dep variable: t- } \\
\text { statistic }\end{array}$ & $\begin{array}{c}\text { MST } \\
\text { Dep variable: log (t-statistic } \\
\text { in absolute values) }\end{array}$ \\
\hline $\begin{array}{c}\text { Explanatory } \\
\text { variables }\end{array}$ & & & \\
\hline Intercept & $-1.48(0.55)^{* *}$ & $-1.47(1.56)$ & $1.20(0.77)$ \\
\hline $1 /$ SE & $-0.0048(0.009)$ & - & - \\
\hline sqrt (sample size) & - & $-0.002(0.11)$ & - \\
\hline $\log (\mathrm{df})$ & - & - & $-0.14(0.16)$ \\
\hline $\mathrm{N}$ & 45 & 46 & 0.043 \\
\hline $\mathrm{R}^{2}$ & 0.0048 & 0.0001 & \\
\hline
\end{tabular}

Note 1: Collins \& Downes' (1977) study cannot be included in some tests since neither coefficients nor standard errors are reported.

Note 2: Standard errors in parentheses (robust to heteroskedasticity and adjusted by correlation between observations in the same study).

Note 3: Significance at the 1 percent $(* * *), 5$ percent $(* *), 10$ percent $(*)$ level.

Table 5. FAT-Metaregression estimates (OLS)

\begin{tabular}{|c|c|c|c|c|}
\hline Mod. Variables & \multicolumn{2}{|c|}{ Full Sample } & \multicolumn{2}{c|}{ Studies for solid waste } \\
\hline & Model 1: 1/SE & $\begin{array}{c}\text { Model 2: sqrt } \\
\text { (sample size) }\end{array}$ & Model 1: 1/SE & $\begin{array}{c}\text { Model 2: sqrt } \\
\text { (sample size) }\end{array}$ \\
\hline 1/SE & $-0.006(0.0049)$ & - & $-0.0051(0.0041)$ & - \\
\hline sqrt (sample size) & - & $-0.003(0.12)$ & - & $0.04(0.13)$ \\
\hline Year & $0.11(0.03)^{* * *}$ & $0.11(0.033)^{* * *}$ & $0.14(0.03)^{* * *}$ & $0.14(0.03)^{* * *}$ \\
\hline Functional_form & $-0.92(1.03)$ & $-0.64(1.06)$ & $-0.36(1.20)$ & $0.07(1.15)$ \\
\hline Service & $-1.73(0.99)^{*}$ & $-1.50(0.90)$ & - & - \\
\hline USA & $1.65(0.87)^{*}$ & $1.86(0.90)^{* *}$ & $1.95(1.0007)^{*}$ & $2.24(0.96)^{* *}$ \\
\hline UK & $0.59(0.72)$ & $0.58(1.18)$ & $0.91(0.75)$ & $0.64(1.28)$ \\
\hline Panel & $-2.80(0.61)^{* * *}$ & $-2.87(0.82)^{* * *}$ & $-2.86(0.57)^{* * *}$ & $-3.04(0.88)^{* * *}$ \\
\hline Intercept & $-228.14(67.03)^{* * *}$ & $-221.11(65.66)^{* * *}$ & $-291.07(59.72)^{* * *}$ & $-285.13(57.86)^{* * *}$ \\
\hline $\mathrm{R}^{2}$ & 0.38 & 0.33 & 0.42 & 0.37 \\
F (joint sig.) & $7.69 * * *$ & $5.01 * * *$ & $8.222^{* *}$ & $6.08^{* * *}$ \\
$\mathrm{~N}$ & 45 & 46 & 37 & 38 \\
\hline
\end{tabular}

Note 1: Standard errors in parentheses (robust to heteroskedasticity and adjusted by correlation between observations in the same study).

Note 2: Significance at the 1 percent $(* * *), 5$ percent $(* *), 10$ percent $(*)$ level.

Note 3: The variable of service is significant at the 11 percent level in the estimation that uses the square root of the sample size as explanatory variable. 